\title{
Investigation of safety applications benzylpenicillin sodium salt after exposure to a pulsed magnetic field
}

\author{
(C) Natalia A. Rodenko, ${ }^{1,2+}$ Tatiana I. Vasilieva, ${ }^{1}$ Irina A. Belyaeva, ${ }^{2}$ \\ Vladimir A. Gluschenkov, ${ }^{2}$ Peter P. Purygin, \\ Alexander V. Samorodov, ${ }^{4}$ and Linara I. Bashirova ${ }^{4}$ \\ ${ }^{1}$ Department of Biochemistry, Biotechnology and Bioengineering. ${ }^{3}$ Department of Inorganic Chemistry. \\ Samara National Research University Named after academician S.P. Korolev. Pavlova St., 1. Samara, \\ 443000. Russia. Phone: +7 (846) 334-54-59, +7 (846) 334-54-45. \\ E-mail:vastaty@rambler.ru,puryginpp2002@mail.ru \\ ${ }^{2}$ Department of Metal Forming. Samara National Research University Named after academician S.P. \\ Korolev. Moscow highway, 34. Samara, 443086. Samara region. Russia. Phone: +7 (846) 267-46-05. \\ E-mail:vgl@ssau.ru \\ ${ }^{4}$ Department of Anesthesiology and Resuscitation with the Course of Idpo. Bashkir State Medical University. \\ Lenin St., 3. Ufa, 450000.Russia.Phone:89050060385.E-mail:AVSAMORODOV@GMAIL.COM
}

*Supervising author; ${ }^{+}$Corresponding author Keywords: complex of physical factors, yield, pre-treatment, magnetic field, peroxidase, catalase, oxidant enzymes.

\section{Abstract}

Pulsed magnetic fields are widely used in various fields of modern technology. In our previous works it was shown the strengthening of antibacterial properties of benzylpenicillin sodium salt after exposure to a pulsed magnetic field of high tension. The reason for this may be a change in the conformation of $\beta$-lactam antibiotics under external physical influence, which increases the affinity of benzylpenicillin molecules to the active center of penicillin-binding proteins.

This article presents studies on the safety of benzylpenicillin sodium salt irradiated by a pulsed magnetic field. Benzylpenicillin sodium salt in powdered form was irradiated with a pulsed magnetic field with the intensity $\mathrm{H}=(0.09 \cdot 106-1.23 \cdot 106) \mathrm{A} / \mathrm{m}$, frequency $\mathrm{f}=30-70 \mathrm{kHz}$, and a different number of pulses $(\mathrm{n}$ $=1-3)$, using inductors - single-turn and multi-turn.

The influence of pulsed magnetic field on chemiluminescence parameters of irradiated benzylpenicillin sodium salt was studied. The appearance of free radicals in irradiated preparations was evaluated in simple model systems simulating the most common free radical oxidation reactions in the body and in environments in which the formation of reactive oxygen species and lipid peroxidation reactions was initiated. Acute toxicity in intraperitoneal administration of antibiotic to mice before and after treatment with pulsed electromagnetic field with calculation and comparison of $\mathrm{LD}_{50}$ indices was also investigated.

It was found that the treatment of the dry substance benzylpenicillin sodium salt by a pulsed magnetic field does not cause the formation of free radicals and is not accompanied by an increase in the toxicity of this antibiotic. The possibility of using new ways to increase the antibacterial activity of antibiotics without increasing their concentrations is considered.

\section{References}

[1] D.V. Leontyeva, A.I. Cihlarova, T.A. Kurkina. Variation of morphological structure of blood serum of rats-carriers of tumours under the influence of magnetic and electric fields. Siberian journal of Oncology. 2009. Vol.51. No.1. P.121-123. (russian)

[2] V.N. Kazin, E.A. Guzov, E.M. Pliss, V.A. Moshareva, V.V. Makarin, N.Yu. Levshin, A.A. Baranov. The Influence of a constant magnetic field on the components of protein structures of human blood [Text]. Biophysics. 2017. Vol.62. No.5. P.998-1007. (russian)

[3] V.V. Novikov, E.V. Yablokova, E.E. Fesenko. The effect of combined magnetic fields with a very weak variable low-frequency component on luminol-dependent chemiluminescence of mammalian blood [Text]. Biophysics. 2015. Vol.60. No.3. P.530-533. (russian) 
[4] M. Pliss Evgeny, M. Grobov Aleksey, K Kuzaev Anton, A.L Buchachenko. Magnetic field effect on the oxidation of organic substances by molecular oxygen [Text]. Journal of Physical Organic Chemistry. 2018. Vol.23. P.3915-3927.

[5] Bozic Mojca, Lucija Crepinsek Lipus, Vanja Kokol. Magnetic Field Effects on Redox Potential of Reduction and Oxidation Agents [Text]. Magnetic field effects on redox ptential. 2008. Vol.81. P.413421.

[6] A. Szczes, E. Chibowski, L. Holysz, P. Rafalski. Effect of static magnetic field on water at kinetic condition [Text]. Chem. Eng. Process. 2011. Vol.50. P.124-127.

[7] Evelyn J.L. Toledo, Teodorico C. Ramalho, Zuy M. Magriotis. Influence of magnetic field on physicalchemfcal properties of the liquid water: Insights from experimental and theoretical models [Text]. Journal of Molecular Structure. 2008. Vol.8. P.409-415.

[8] V.N. Kondratyev. Magnetic Field Effect on Masses of Atomic Nuclei [Text]. T. Maruyama, S. Chiba. Astrophysical Journal. 2001. Vol.2. P.1137-114.

[9] D.A. Usanov, A.E. Pustelga, A.D. Usanov. Dielectric permittivity and tangent of dielectric loss angle of water at microwave frequencies under the combined action of low-frequency and permanent magnetic fields. Physics of wave processes and radio engineering systems. 2009. Vol.12. No.1. P.34-38. (russian)

[10] S.A. Vshivkov, E.V. Rusinova. Influence of magnetic field on phase transitions in solutions of cellulose derivatives. High molecular weight compounds. Series A. 2008. Vol.50. No.7. P.1141-1149. (russian)

[11] S.N. Peschanskaya, P.N. Yakushev. Creep of polymers in a constant magnetic field. Solid state physics. 1997. Vol.39. No.9. P.1690-1692. (russian)

[12] G.V. Maksimov, A.V. Nagovitsyn. Role of low-molecular proteins in the implementation of the action of laser radiation and alternating magnetic field on blood. Bulletin of Moscow University. Episode 16. 2009. No.3. P.8-12. (russian)

[13] N.V. Alexeeva, I.P. Osnovina, E.L. Vladimirtseva, A.V. Ivanov. Substantiation of possibility of application of magnetophoresis in the pathology of the joints [Text]. Questions of balneology, physiotherapy and physical therapy. 2018. No.3. P.49-56. (russian)

[14] V.A. Glushchenkov, V.F. Karpukhin. Technology of magnetic-pulse processing of materials. Samara: Publishing house Fedorov. 2014. 208p. (russian)

[15] V.A. Glushchenkov. Power plants for magnetic pulse processing of materials. Samara: Fedorov publishing house. 2013.123p. (russian)

[16] V.A. Glushchenkov. Inductors for magnetic pulse processing of materials. Samara. Publishing house: Educational literature. 2013.146p. (russian)

[17] V.A. Glushchenkov, T.I. Vasilyeva, P.P. Purigin, I.A. Belyaeva, Rodenko N.A., Madyarova A.K., Jusupov R.Ju. Changes of the Antibacterial Activity of Benzylpenicillin as a Result of Exposure to Pulsed Magnetic Field of High-Intensity. Biophysics. 2019. Vol.64. Iss.2. P.214-223.

[18] T.I. Vasilyeva, I.A. Belyaeva, V.A. Glushchenkov, N.A. Rodenko. Magnetic effects of antibacterial action of irradiated benzylpenicillin sodium salt. News of Samara scientific center of RAS. 2018. Vol.20. No.5-2. P.307-316. (russian)

[19] M.G. Baryshev, A.A. Basov, G.F. Kopytov et al. Study of the influence of low-frequency electromagnetic field on the processes of free radical oxidation. Ecological Bulletin of the BSEC research centers. 2014. No.1. P.12-17. (russian)

[20] V.A. Glushchenkov, T.I. Vasilyeva, I.A. Belyaeva and others. Influence of pulsed magnetic field on antibacterial activity of benzylpenicillin of sodium salt. Actual problems of biological physics and chemistry. 2018. Vol.3. No.4. P.814-817. (russian)

[21] N.A. Rodenko. Influence of pulsed magnetic field (PMF) on antibacterial activity of benzylpenicillin of sodium salt. XLV Samara regional student scientific conference. 2019. Iss.2019. Part 1. P.79. (russian)

[22] Assessment of the toxicity and hazard of chemicals in their mixtures for human health [Text]: guidance I. V. Bragina [et al.], resp. ed. A. Yu. Popov. Moscow: Rospotrebnadzor. 2014. 638p. (russian)

[23] P.P. Farkhutdinov, S.I. Tevdoradze. Methods of research of chemiluminescence of biological material on chemiluminometer CL - 003. Methods of evaluation of antioxidant activity of biologically active substances for therapeutic and preventive purposes: Collection of reports. Moscow. Russia. 14-15 September 2004. Under the General editorship of Professor E. B. Burlakova. Moscow: Publishing house of PFUR. 2005. P.147-154. (russian) 